\title{
CAMINHOS PARA TIC EM SALA DE AULA SOB A PERSPECTIVA DOS PROFESSORES
}

\author{
PATHWAYS TO ICT IN THE CLASSROOM FROM THE PERSPECTIVE OF \\ TEACHERS
}

\author{
Maíra DARIDO DA CUNHA ${ }^{1}$ \\ José Luís BIZELLI ${ }^{2}$
}

RESUMO: As novas tecnologias da informação e da comunicação - TIC - ditam um novo cenário para sala de aula. Muitas são as expectativas de aprendizagem por meio desta nova ferramenta. Para tanto, é preciso pensar na mudança de paradigmas sob a ótica do professor, agente fundamental no processo de aprendizagem dentro da escola. A seguinte pesquisa buscou identificar os limites e as possibilidades do uso das TICs em sala de aula, elencando as principais mudanças necessárias para efetivação dentro deste processo. Foram ouvidos 150 professores e 7 diretores, distribuídos em 10 escolas estaduais do município de Piracicaba - SP. Diante dos resultados da pesquisa, tornou-se fundamental repensar práticas escolares, entender TIC como meio a mais de fomentar discussão crítica entre professores a fim de traçar caminhos que orientem prática docente criativa e reflexiva, em que TIC poderiam ser compreendidas como espaço de possibilidade de criação, individual ou colaborativa e não apenas utilizada como forma de chamar a atenção de alunos ou de sensibilizá-los aos conteúdos propostos na aula.

PALAVRAS-CHAVE: TIC. Professores. Escola.

ABSTRACT: The new information and communication technologies - ICT - dictate a new scenario for the classroom. Many are the expectations of learning through this new tool. To do so, we must think of the paradigm shift from the point of view of the teacher, a fundamental agent in the learning process within the school. The following research sought to identify the limits and possibilities of the use of ICTs in the classroom, listing the main changes needed to be effective within this process. A total of 150 teachers and 7 directors were interviewed, distributed in 10 state schools in the city of Piracicaba - SP. In view of the results of the research, it has become fundamental to rethink school practices, to understand ICT as a means to foster critical discussion among teachers in order to outline ways to orient creative and reflective teaching practice, in which ICT could be understood as a space of possibility of Creation, individual or collaborative and not only used as a way to attract the attention of students or to sensitize them to the contents proposed in the lesson.

KEY-WORDS: ICT. Teachers. School.

${ }^{1}$ Doutoranda e Mestre pelo Programa de Pós-Graduação em Educação Escolar. Faculdade de Ciências e Letras - Unesp Araraquara. maira_darido@yahoo.com.br

${ }^{2}$ Livre Docente do Departamento de Antropologia, Filosofia e Política. Faculdade de Ciências e Letras Unesp Araraquara. bizelli@fclar.unesp.br 


\section{Introdução}

É na segunda metade do século XIX, que a Europa é remodelada pelo surgimento das indústrias e a explosão das tecnologias, e com isso grande contingente humano foram lançados em um ambiente onde nada se assemelhava ao transtorno da existência coletiva até então existente, isto é, à repetição, à preservação dos costumes, às relações personalizadas, à preponderância dos laços morais (MISSIO; CUNHA, 2014).

Essa industrialização e consequente urbanização abalaram as estruturas sociais, varrendo rotinas e referências estabelecidas, pois provocaram profundas alterações nas formas de trabalho, na tecnologia, na produtividade, nas aglomerações humanas, nos meios de comunicação etc. (FRIDMANN, 1999). Essa nova configuração tem como um dos agentes responsáveis o constante desenvolvimento tecnológico, exacerbado no último século.

Lévy (2004) analisa o aprimoramento das tecnologias como um novo momento de desenvolvimento humano, em que, por meio de múltiplas formas de produzir conhecimento, refletem-se outras necessidades, desejos e comportamentos, que assumem diferentes direcionamentos na organização social.

Embora estejamos muito acostumados a nos referir à tecnologia apenas para computadores, televisão, celulares e artigos ligados à informática, o termo tecnologia engloba a totalidade de coisas que a engenhosidade do cérebro humano conseguiu criar em todas as épocas, suas formas de uso, suas aplicações (KENSKI, 2010).

A linguagem digital é o aperfeiçoamento de uma das tecnologias mais importantes utilizadas pelo homem: a linguagem. Assim, a linguagem digital mostrou novas perspectivas de comunicação, quebrando a antiga noção de fronteiras, garantindo novas formas de produção e propagação de informações e a interação e a comunicação em tempo real. A essa forma de ver o mundo deu-se o nome de NTIC, novas tecnologias da informação e da comunicação. Com o tempo, segundo Kenski (2010), elas foram se incorporando ao cotidiano e ficaram simplesmente TIC: tecnologias da informação e da comunicação.

O termo TIC teria surgido da fusão de três grandes vertentes técnicas da atualidade, que são: a informática, as telecomunicações e as mídias eletrônicas 
(BELLONI, 2005). Ademais, tanto para Sancho (2006) quanto para Lévy (1998), as TIC apontam para um novo direcionamento na organização social, propagando novos locais para troca, compartilhamento e divulgação de informações: o ciberespaço.

A propagação e constante aperfeiçoamento das TIC não se restringem apenas aos novos usos de determinados equipamentos e produtos, mas engloba também a alteração de comportamentos, a criação de novos padrões culturais e a transformação não apenas do comportamento individual, mas daquele de toda uma sociedade (GIDDENS, 2002).

Nesse cenário, é possível identificar como todo esse avanço tecnológico exerceu forte impacto sobre as diversas instituições sociais, bem como nas relações familiares, na cultura, na identidade e, consequentemente, na educação (BELLONI, 2005). Bianchi e Hatje (2007) afirmam que esta evolução ao reconfigurar as formas de tempo e espaço tem provocado justamente essas rápidas transformações nas diferentes formas de representações sociais que precisam ser refletidas e analisadas com responsabilidade crítica.

Transportando a discussão para o cenário da educação, pode-se afirmar que o aperfeiçoamento das Tecnologias da Informação e da Comunicação (TIC), conduz a um novo paradigma do processo ensino/aprendizagem, modificando os papéis dos atores escolares.

TIC ocupam um espaço significativo dentro dessa nova ordem social, criando diferentes maneiras de se comunicar, informar e interagir, permeando ambientes cada vez mais diversificados. Muitas questões na modernidade envolvem as tecnologias, principalmente em relação a sua utilização em ambientes educacionais (BIZELLI, 2013). Debates sobre os limites e as dificuldades que os professores encontram em abordá-las no contexto pedagógico, por exemplo, são cada vez mais recorrentes.

No que tange especificamente ao contexto educacional, faz-se necessário ampliar os espaços de debate, visto que a inserção das tecnologias na escola parece não ter acompanhado o mesmo ritmo das demais instituições sociais.

Acredita-se, nesse estudo, que não se pode negar a importância de TIC no cotidiano escolar e do auxílio das mesmas para o processo educativo, mas é ingenuidade considerar que elas resolverão todos os problemas educacionais. Muitos acreditam que 
TIC são necessárias para uma educação de qualidade, porém, se a melhoria do ensino dependesse apenas da introdução das TIC nas escolas, melhores soluções teriam sido encontradas há algum tempo considerando os investimentos realizados em diferentes nações. Deve-se pensar como inseri-las de maneira efetiva na escola para proporcionar aos alunos uma aprendizagem significativa (BIZELLI, HEREDERO, 2016). Assim, são fundamentais as reflexões e debates sobre o uso de TIC em sala de aula e seu processo de implantação nas escolas.

Com essa demanda, um enorme esforço do ponto de vista político para a compra e elaboração de programas que garantam o seu uso nas escolas. Os altos gastos com programas que visam à inserção de TIC nas escolas, muitas vezes, se mostram pouco eficientes, já que não vêm acompanhados de medidas que melhorem as condições de trabalho do professor, infraestrutura das escolas, formação continuada dos professores e diferentes metodologias utilizadas no processo de ensino/aprendizagem.

Nessa esteira, buscou-se, nesse estudo, investigar a visão dos professores acerca de TIC no ambiente escolar. De que forma, na voz dos docentes as TIC, estão sendo incorporadas na escola? No que concerne à visão dos professores, quais os limites e possibilidades do uso delas no processo de ensino/aprendizagem?

A pesquisa apresentada é de natureza qualitativa e foi realizada no município de Piracicaba, interior do Estado de São Paulo. Para tanto, foram aplicados questionários para 150 professores que lecionam no Ensino Médio da rede estadual de ensino de São Paulo. Em continuidade, foram realizadas entrevistas semiestruturadas com um grupo de professores e diretores para que houvesse um aprofundamento das questões levantadas pelos professores no questionário. A pesquisa tem uma amostragem de 150 professores e 7 diretores, distribuídos em 10 escolas do município de Piracicaba, escolhidas aleatoriamente pelo dirigente de ensino responsável pela Diretoria de Ensino de Piracicaba.

\section{Entrando na escola: as TICs em sala de aula}

Questionados sobre a importância do uso de TIC, 49\% dos professores acreditam que o uso de TIC nos espaços escolares é muito importante, 39\% acha importante, $11 \%$ julga pouco importante e $1 \%$ acredita que o uso de TIC nas escolas é irrelevante. Se agruparmos os professores que julgam muito importante ou importante o 
uso de TIC no contexto escolar, temos o total de $88 \%$ dos professores; já os que acham pouco importante ou irrelevante somam 12\% (DARIDO DA CUNHA; BIZELLI, 2015).

Os dados apresentados apontam uma consonância entre os esforços para implantação de TIC nas escolas e a opinião dos professores. TIC estão em todos os contextos da vida dos adolescentes, dessa forma, seria estranho se não estivesse presente no processo de ensino/aprendizagem.

Segundo a fala de um professor entrevistado, "É preciso ter tecnologia nas escolas, e tecnologia de ponta". É inaceitável que os alunos tenham, na escola, menos do que têm em casa. As tecnologias fazem parte do dia a dia de qualquer cidadão, seria muito estranho elas estarem fora da escola".

Compreendendo que os professores consideram como muito importante ou importante o uso de TIC, é necessário reconsiderar as práticas e refletir sobre o uso de TIC como um meio e uma ferramenta para repensar o processo de ensinoaprendizagem. Há uma tendência em abordar a questão de TIC e pensar nas "velhas" maneiras de abordar a educação.

Segundo afirma Lévy (1999, p.30), a educação conta com diversos benefícios da cibercultura, em termos de tecnologias e possibilidades comunicacionais e relacionais. Por outro lado, conforme explica Magalhães e Mill (2013),

Há também riscos e dificuldades no ensino-aprendizagem em tempos de cibercultura, como por exemplo: o isolamento potencial, a sobrecarga cognitiva, a dominação e a exploração, a "bobagem coletiva", a dependência. (2013, p. 322)

Apesar de entender os perigos de usar TIC sem uma reflexão prévia, entende-se que TIC dominam o cotidiano de pessoas de diferentes idades, principalmente dos jovens, dos diversos níveis de escolaridade e classes sociais. São utilizadas no trabalho, nos serviços domésticos, na comunicação, no lazer e na educação (MORAN, 1995).

Corroborando com Belloni (2005) sobre a importância de TIC,

É preciso também não se esquecer que, embora estas técnicas ainda não tenham demonstrado toda sua eficácia pedagógica, elas estão cada vez mais presentes na vida cotidiana e fazem parte do universo dos jovens, sendo esta a razão principal da necessidade de sua integração à educação (BELLONI, 2005, p. 25). 
Outra questão presente no questionário diz respeito à crença dos professores sobre mudança na aula com uso de TIC, incitando-os a apontar qual seria ou a justificar a descrença nas inovações para a dinâmica da sala de aula.

Das respostas, $62 \%$ apontaram que há muitas mudanças na aula com o uso de TIC, 28\% apontaram que há mudanças com o uso de TIC. 9\% dos professores apontaram que há poucas mudanças com o uso de TIC e 1\% apontou não acreditar haver mudanças nas aulas com o uso das TIC.

Assim, 90\% dos professores acreditam que há muitas mudanças ou que há mudanças em uma aula com o uso de TIC e 10\% acreditam que há poucas mudanças ou que não há nenhuma mudança. Nesse sentido, um dos entrevistados, afirma que "Os alunos prestam mais atenção quando eu uso TIC em sala de aula, sinto diferença, mas isso não é determinante, é preciso ter claro qual o objetivo da aula e qual conteúdo quer passar. TIC ajudam a gente a dar aula, mas não nos substitui nessa empreitada".

O processo de inserção de TIC na escola gera transformações na prática docente e na revisão de metodologias do processo de ensino-aprendizagem. Esse novo processo interfere diretamente na relação professor/aluno, fomentando a necessidade de reflexão sobre as mudanças, vantagens e desvantagens de TIC em sala de aula.

Quando os professores foram questionados se estavam preparados para o uso de TIC em sala de aula, as respostas chamaram a atenção. Apenas $15 \%$ dos professores apontam se sentirem preparados para utilizar TIC na sala de aula, enquanto $79 \%$ deles afirmam não estarem preparados e $6 \%$ apontam estarem preparados parcialmente (DARIDO DA CUNHA; BIZELLI, 2015).

Esse dado reflete a relação complexa do professor perante TIC, pois, apesar de majoritariamente acreditarem que o uso destas é importante, apenas $15 \%$ se sentem seguros em usá-las. É preciso pensar nos impactos que o bombardeamento de TIC pode causar no ambiente escolar. O uso de TIC sugere nova lógica no modelo de aulas, planejamento, currículos e até na comunicação e organização escolar. O processo de inserção de TIC na escola extrapola a questão da infraestrutura e caminha para uma reflexão sobre o choque cultural promovido pela convivência e mudanças geracionais. A inserção de TIC no ambiente escolar é também inserção na vida dos professores, que, por vezes, não as usam frequentemente, ou não as usam tanto quanto seus alunos.

A questão geracional, de fato, é algo que nos chama a atenção. Se essa questão fosse tabulada por faixa etária, $100 \%$ dos professores com até 30 anos se sentem preparados para o uso de TIC em sala de aula, enquanto $90 \%$ dos professores acima de 
50 anos afirmam não estarem preparados, dados que remetem à questão dos nativos digitais.

As mudanças desenfreadas causadas pela Modernidade Líquida (BAUMAN, 2001), se refletem na necessidade de reconstruir frequentemente os elementos cotidianos o que, para Bauman (2001), gera uma insegurança para lidar com questões que se renovam cotidianamente e de forma brusca. Para o autor (BAUMAN, 2001, p. 35), esse é o mal-estar da docência: “[...] no admirável mundo novo das oportunidades fugazes e das seguranças frágeis, as identidades ao estilo antigo, rígidas e inegociáveis, simplesmente não funcionam".

O professor é peça chave para o desdobramento de TIC em um processo de ensino e aprendizagem mais eficaz. Dessa forma, é preciso se aprofundar nas reflexões e entender que muitos docentes são "imigrantes digitais" com o compromisso de ensinar "nativos digitais", que aprendem em ritmos e de maneiras diferentes, havendo, desse modo, um choque cultural geracional muito grande na relação professor e aluno, acentuando ainda mais a crise dessa relação.

\section{Limites e possibilidades: as TICs e a educação}

Para Arendt (2000), a crise na educação é um reflexo da crise por que a sociedade moderna passa. Dessa forma, para compreender os problemas na escola, é preciso analisar a sociedade em que ela está inserida. Segundo Cambi (1999, p. 203),

[...] a modernidade nasce como uma projeção pedagógica que se dispõe, ambiguamente, na dimensão da libertação e na dimensão do domínio, dando vida a um projeto complexo e dialético, também, contraditório, animado por um duplo desafio: o de emancipação e o de conformação, que permaneceram no centro da história moderna e contemporânea como uma antinomia constitutiva, talvez não superável, ao mesmo tempo estrutural e caracterizante da aventura educativa do mundo moderno.

A crise na educação, como a própria Arendt (2000) sugere no início de sua discussão, não é má em si mesma, ela é uma possibilidade de se repensar práticas cotidianas inerentes à sociedade moderna. A dicotomia se centra na questão da novidade e conservação que experimentamos na existência humana histórica. 
Essa dicotomia pode ser observada quando os professores são questionados sobre se usam TIC em sala. Dos entrevistados, $45 \%$ dos docentes apontaram que usam quando possível; $23 \%$, que usam raramente; $17 \%$, que usam muito; $8 \%$, que nunca usam e $7 \%$ diz não usar por não ter acesso na escola.

Dado relevante é o fato de que $88 \%$ dos professores apontaram achar importante o uso de TIC em sala de aula e apenas $62 \%$ apontarem que usam muito ou quando possível. Essa reflexão ajuda a desvendar dois aspectos centrais: o motivo por que $26 \%$ dos professores não usam, apesar de acharem TIC na sala de aula importante e o porquê de $38 \%$ dos professores apontarem que usam raramente, nunca usam ou que não têm acesso a TIC nas escolas.

Apenas $17 \%$ dos professores apontaram que usam muito TIC em sala de aula e $45 \%$ usa quando possível. Mas, se somarmos aqueles que usam raramente, nunca usam ou não têm acesso a TIC nas escolas, chegamos à porcentagem de $38 \%$. O discurso em questão gera embates dentro do próprio contexto escolar e permeiam a esfera da condição de trabalho do professor da Rede Estadual de São Paulo.

O número apresenta o retrato das escolas de Piracicaba, onde calcula-se um investimento grande na infraestrutura e não se considera uma porcentagem efetiva de professores que afirmam utilizar TIC nas escolas. Sobre os apontamentos feitos pelos professores nos questionários e na entrevista:

Esse ano eu dou aula em três escolas. Tive que fazer isso para complementar minha carga. Em todas as escolas que dou ou já dei aula, todas elas têm um monte de computador dentro de caixas que demoram anos ou nunca foram instalados [..] $\mathrm{E}$ aí quando a gente questiona a situação, eles [a equipe gestora] falam que já abriram chamado na Secretaria de Educação e que não podem fazer nada se não esperar [..]. Também tem quando o computador quebra e não tem mais jeito, não tem o que fazer com ele, não pode jogar fora porque é bem, ai eles ficam lá, ocupando espaço e poluindo a visão de todo mundo na escola, parece um grande cemitério de computadores que mau foram usados.

O professor, durante a entrevista, afirmou que a maior dificuldade no uso de TIC envolve a baixa quantidade e diversidade de materiais que a escola oferece e o grande processo burocrático para manutenção e instalação dos equipamentos.

Infelizmente, o uso de TIC na educação ainda esbarra nas questões estruturais, na falta de equipamentos e sua manutenção (CHAMPANGNATTE; NUNES, 2011), requisitos básicos para que o trabalho com as tecnologias seja realizado de modo 
adequado. Mesmo com todo o investimento dos programas governamentais, verificouse que, nas escolas, segundo os professores, a manutenção de TIC não é realizada nem frequente nem adequadamente.

Outra questão levantada pelos professores foi o tempo disponível para elaboração das aulas com TIC, ou, até mesmo, o tempo para instalação do recurso a cada aula:

Tenho dois cargos na Rede, preciso disso para pagar minhas contas e sustentar minha família. Trabalho de manhã, tarde e noite, os ATPCS são para resolver questões burocráticas e dar dura nos professores. Que horas que vou preparar minhas aulas?

De outro entrevistado: "Eu poderia me esforçar mais para aprender a usar, mas dou 50 aulas semanais, não tenho tempo de organizar minhas cadernetas, muito menos pensar numa aula em que eu possa inserir TIC".

As condições de trabalho refletem diretamente na qualidade de ensino ofertado. Devido aos baixos salários, os professores sentem a necessidade de acumular funções, jornadas de trabalho ou mais de um emprego. No questionário, 69\% dos professores apontaram acúmulo de função, ou seja, além de darem aula como efetivos em alguma escola, possuem outros empregos ou dão aulas em escolas particulares. Número alarmante e na contramão da busca de melhorar a qualidade da educação. Evidencia-se, portanto, a necessidade de melhoria dos salários dos professores, condições de trabalho e valorização social da função docente.

A falta de tempo, a falta de capacitação e a falta de infraestrutura da escola foram duas respostas que apareceram com frequência nas entrevistas realizadas com os professores quando questionados do porquê não usavam TIC em suas aulas:

Fiz alguns cursos para usar o computador, o celular, sei ligar e fazer as coisas básicas. Mas as vezes que tentei usar em sala de aula, só me deu dor de cabeça, faltava cabo, faltava adaptador, não tinha tomada suficiente, ninguém achava a caixa de som. Ou seja, fiquei mais da metade da aula para tentar ligar o equipamento e não deu certo. A gente planeja a aula em casa, faz tudo "esquematizadinho" e, na hora, é vencido por uma extensão. Material tem, mas é preciso organizar tudo isso também.

A mesma questão foi feita aos diretores que apresentaram diferentes hipóteses para o baixo uso de TIC na escola e confirmaram a baixa adesão dos professores quanto 
ao seu uso. Apenas 1 diretora, da única escola de Tempo Integral, teve uma resposta oposta às dos demais diretores:

Os professores usam todos os dias os recursos tecnológicos. Foi preciso implementar um sistema de reserva e compramos mais computadores, telões e projetores. Hoje quase todas as salas são equipadas com esses recursos, mas é porque os professores usam bastante, tiveram cursos, há momentos de troca de experiência, aprenderam a usar os recursos para prender a atenção dos alunos e para dinamizar suas aulas.

A fala da diretora da escola de tempo integral destoa dos demais diretores, fazendo-nos refletir sobre a nova proposta da escola de tempo integral, em que o professor deve ter dedicação exclusiva, espaços para troca de experiência com os demais professores e cursos e aperfeiçoamentos que a direção da escola julgue necessário para aquele contexto.

Todos os outros 7 diretores foram na contramão desse discurso, apontando, no geral, 3 hipóteses para o não uso de TIC em sala de aula: a resistência do professor com o uso de TIC e novas possibilidades na educação; a insegurança do professor, fator que pode estar relacionado com as poucas formações para uso e; a falta de tempo para estudo e preparo das aulas utilizando TIC. Conforme a fala de um diretor:

A gente sabe que os professores não usam, porque, para usar, têm que preparar bem a aula, coisas que a gente sabe que pouquíssimos fazem, a maioria usa uma sequência de exercícios e textos que prepararam há anos atrás e usam por muito tempo, não querem saber de coisas novas.

Nessa fala, evidencia-se a questão da resistência do professor em renovar suas práticas e repensar as metodologias no processo de ensino/aprendizagem. O diretor em questão coloca que a maioria dos professores não quer saber de coisas novas, ou não se sente motivada a aprender a utilizar TIC. Por outro lado, um diretor afirma:

É preciso dar tempo para essa renovação, o professor, por sua condição de trabalho, não tem tempo nem motivação para pensar em aulas que usem computadores, tablets e outros recursos, acabam fazendo mais do mesmo com as tecnologias.

Sobre a insegurança dos professores, um diretor aponta:

Alguns professores têm medo de usar, porque eles sabem que os alunos sabem usar melhor que eles. É como se der algo errado, ele vai 
ser menos que os alunos. Tem professor que não gosta de pedir ajuda para o aluno, ou acha que isso é mostrar que não é um bom professor.

Aqui, o diretor entrevistado aponta para o medo e insegurança do professor para usar TIC em sala de aula. O fato de TIC serem dominadas pelos jovens rompe com a visão tradicional de educação, onde o professor seria o detentor do conhecimento e teria como função depositar no aluno todo seu conhecimento - a chamada educação bancária (FREIRE, 1993).

A escola pública enfrenta muitos problemas, como a falta de estrutura, recursos e de professores. De acordo com Belloni (2005), “[...] tentativas de melhoria da qualidade do ensino, através da introdução de inovações tecnológicas e metodológicas esbarram de modo geral em obstáculos pedagógicos e institucionais que as condenam ao fracasso" (BELLONI, 2005, p. 87)

Ainda segundo Belloni (2005) e Pretto (2008), a escola pode diminuir as desigualdades existentes em relação ao acesso às tecnologias, incluindo-as no seu contexto. Além da introdução de um suporte tecnológico adequado, os autores consideram a necessidade de transformações metodológicas no processo de ensinoaprendizagem. Segundo um professor:

\begin{abstract}
Acho importante usar, mas sinto um pouco de exagero, sempre é necessário comprar algo novo, antes era fios, hoje são softwares, parece que nunca vai ser o suficiente para eles aprenderem. O que é novo prá gente pros alunos já é tudo normal, corriqueiro [...] na verdade é uma tentativa da escola de se situar no tempo deles, já que a escola está anos luzes atrás deles e de suas vontades.
\end{abstract}

A fala do professor remete a questões ainda mais profundas do que as de infraestrutura ou de formação continuada para professores. A afirmação refere-se ao constante desinteresse dos alunos na sala e reprodução daquilo que vivem no âmbito escolar. A constante mudança, característica da sociedade atual, traz à tona reflexões sobre a velocidade das transformações.

Bauman (2001) afirma que a marca da modernidade é a "vontade de liberdade", capaz de acompanhar a velocidade das mudanças econômicas, tecnológicas, culturais e do cotidiano. Neste mundo, não há como se sentir seguro e estável, pois é tudo muito incerto e porque não dizer, assustador. Isso porque as questões modernas não encontram utilidade para a "certeza", para a "segurança", ou mesmo para a "estabilidade". Como 
afirma Bauman (2001), aquele desejo imenso de poder que animou a busca do definitivo desperta, agora, pouco entusiasmo. Já o que desperta grande paixão é o que a sociedade atual nos incita a fazer, que é desempenhar o papel de consumidor.

Outro professor lembra um problema inerente à vida em sociedade, as relações de poder:

O que adianta ter wi-fi nas escolas se os coordenadores não querem passar a senha? Os coordenadores não confiam nos professores, eles veem a gente como inimiga, como se a gente fosse preguiçoso, até parece que não sabem como está a sala de aula. [...] Eles não passam a senha com medo dos professores passarem para os alunos. Como se os alunos precisassem de wifi prá entrar na internet. Fora o que, alguns alunos sabem rackear a senha, independente de quantas vezes por dia os coordenadores mudem.

O relato direciona as relações de poder e problemas presentes em várias escolas, o confronto interno entre professores e professores, professores e alunos e professores e coordenadores. Dessa forma, a vida do professor na escola é permeada de conflitos, dificultando a formação de um espaço aberto para o novo, que se readapte ou que se reconfigure para receber TIC.

É na escola que coexistem inúmeras relações de poder, reformulando as estruturas hierárquicas internas a todo mundo. Logo, é preciso compreender as estruturas de poder de uma sociedade para que se possa entender a dimensão da reprodução social (BOURDIEU, 1997) que existe no espaço escolar. É difícil pensar nos múltiplos problemas sociais, sem entender o seu reflexo na escola.

A partir dessa constituição, a relação entre poder e educação é muito aproximada, uma vez que os moldes escolares modernos têm suas bases firmadas em modelos disciplinares. Assim, ao invés de considerar que existe a construção do saber somente na ausência dos poderes coercitivos, Foucault (1979) faz o caminho reverso e considera que é justamente o poder que se produz o saber. Não há saber que não construa relações de poder e nem poder que não pressuponha um campo de saber.

Baseado no disciplinamento, na vigilância, no controle e no poder, em provas e exames, é possível construir um retrato das práticas e estruturas escolares. Desde a disposição das carteiras, da construção dos corredores até a postura dos professores em sala de aula e na construção do currículo escolar, refletem hierarquias e relações de poder que impõem à multiplicidades de indivíduos condutas unificadas que formam sujeitos disciplinados, obedientes e que, assim, respondem às necessidades das 
instituições geradas pela sociedade moderna. Dessa maneira, é possível dizer que a escola possibilita a realização da modernidade da maneira como ela está (DARIDO DA CUNHA \& SANTOS FILHO, 2013).

O que Foucault (1979) chama de positividade do poder pode ser retratado pela forma como as práticas disciplinares passaram de violentas para sutis e se tornaram, assim, mais eficazes. O poder não reprime a ponto de nos impedir de fazer coisas; ele molda no sentido de nos tornar atuantes de uma produtividade social enquanto sujeitos. Por um bom adestramento, atinge-se uma boa disciplina. A escola é um ambiente propício para a construção de identidade, de sentimento, de responsabilidade, enfim, de um sujeito capaz de atuar dentro dos moldes que a sociedade moderna exige. É, portanto, neste ambiente que se criam os sujeitos através do poder e do saber.

Nesse sentido, é preciso aproximar-se da escola, entender as relações de poder, em qual contexto e sobre quais reflexões se apoiam a inserção de TIC nas escolas para compreender seus usos e desdobramentos dentro das relações de poder e apropriação do conhecimento. Dessa forma, assuntos que deveriam ser compartilhados e recursos que deveriam ser utilizados para a melhoria pedagógica acabam esbarrando em questões hierárquicas e questões que tangem, principalmente, as relações de poder. É preciso ter um bom diálogo entre gestores e professores, com o intuito de ambos objetivarem uma melhoria no processo de ensino/aprendizagem.

Quando questionados, dentre os que usam, de que formas usam TIC em sala de aula, foram assinaladas 112 respostas para transmissão de vídeos, 72 respostas para transmissão de slides e apresentações dos conteúdos sistematizados em aula, 43 respostas para apresentação de trabalho de alunos, 5 respostas para outros fins e apenas 2 respostas para realização de trabalhos em rede. Nessa questão, os professores poderiam assinalar mais de uma opção, sendo as respostas tabuladas por quantidade total e não por porcentagem.

Majoritariamente, as respostas indicam que o uso de TIC nas escolas é restrito à transmissão de vídeos, para projeção de slides e apresentação de trabalhos dos alunos. Apesar dos esforços e investimentos para implantação de TIC nas escolas, nota-se que elas ainda não são usadas como forma de produção do conhecimento.

O movimento de transmissão de vídeo na escola começa na década de 1960, é tratada desde a época de sua inserção como uma prática não reflexiva. Segundo Tardy 
(1976), é nos anos de 1960 a escola não faz uma discussão reflexiva a respeito da gradativa assimilação das imagens cinematográficas e objetivo claro do uso dos vídeos na escola.

Ressalta-se a dificuldade de uso de TIC empregando outras metodologias. Valente (1993) defende que o computador é a ferramenta mais presente no cotidiano dos alunos, devendo ser utilizada na escola. Sua inserção exige a mudança do paradigma educacional, promovendo aprendizagem ao invés de ensino, saindo da pedagogia instrucionista para construcionista, sendo importante que o aluno construa $\mathrm{o}$ conhecimento por meio desta tecnologia. Parece que esse modelo não vem sendo implantado nas escolas.

Além disso, Valente (2013) aponta que a educação com as TIC só tem sentido se estiver integrada ao currículo escolar, quando não se tornam apenas apêndices das aulas ou marketing para a escola. $\mathrm{O}$ autor afirma que é importante o letramento digital dos professores e alunos, ou seja, de não ser um mero apertador de botões (alfabetizado digital), mas sim de ser capaz de usar essas tecnologias em práticas sociais.

Nessa esteira, segundo Lévy (2004), é importante entender as mídias como um meio de transmitir o conhecimento, já que quem direciona o conteúdo ainda é o professor. Mas, não é possível descartar a necessidade de se refletir acerca das novas metodologias para uso de TIC, porque, para fazer "mais do mesmo", não é preciso usar o aparato tecnológico, mas, sim, encontrar caminhos que possibilitem a produção do conhecimento através da ótica digital.

Ainda segundo o autor, há, nesses nossos tempos, uma supervalorização do poder do audiovisual. É preciso refletir para que se quer TIC nas escolas, já que elas podem ser usadas de três maneiras distintas: 1) como uma forma instrumental, de sistematizar as disciplinas em sala de aula, ou seja, como forma ilustrativa; 2) como forma de conhecer a gramática audiovisual, através das linguagens e usufruto dos códigos digitais, voltada para uma lógica de preparação do aluno para o mercado de trabalho; ou, por último, 3) como forma de produção do conhecimento, explorando as facilidades e possibilidades de edição e criação por meio de TIC para inovar a relação do processo de ensino-aprendizagem.

O grande desafio, porém, é delinear estratégias e formas de apropriação de TIC para a produção do conhecimento. É preciso repensar a prática docente no sentido de uma formação para mediar novos conhecimentos através de TIC, direcionando os 
caminhos rumo à aprendizagem significativa e auxiliando no alcance dos objetivos e expectativas de aprendizagem.

\section{Considerações finais}

A complexidade da prática pedagógica exige que estudos e pesquisas que tenham por objetivo investigá-la sejam coerentes com a compreensão dos diversos condicionantes que estão envolvidos. A importância de dar voz aos professores baseiase em entender o agente central das mudanças que vêm sendo incorporadas nas escolas.

A modernidade traz consigo o aumento da velocidade das mudanças e eclode na escola uma possibilidade de mudança, segundo Giddens (1991): "as consequências da modernidade estão se tornando mais radicalizadas e universalizadas do que antes" (1991, p. 13). Essa mudança, no âmbito das instituições escolares, teria como protagonista as tecnologias. Para Shwartzman (1991), as tecnologias devem ser entendidas como a filha bastarda da modernidade, já que seria a protagonista do processo de modernização da sociedade, mas não viria acompanhada de uma reflexão sobre sua inserção.

Por algum tempo, ainda segundo Shwartzman (1991) acreditou-se que o papel do professor com a propagação das TICs estaria "obsoleto", em um segundo plano na esfera educacional. Porém, afirma-se hoje (BELLONI, 2005; LÉVY, 2004; KENSKI, 2007) que o professor é agente fundamental no processo de "modernização" da escola e, principalmente, protagonista no processo de mediação da relação entre a disponibilidade da informação recebida através de TIC e conhecimento.

Nesse sentido, tornou-se fundamental compreender o processo de inserção de TIC em sala de aula, dando voz aos professores. Observou-se que há muitos questionamentos que circunscrevem a prática docente, inclusive no que tange a formulação de políticas públicas. Assim, a possibilidade de dar voz aos professores poderia substanciar medidas que andassem em consonância a realidade da prática docente.

Apesar de todos os dilemas que o professor enfrenta, ele ainda é tido como um dos responsáveis por proporcionar melhorias significativas na educação, como afirma Arroyo (2006) o professor é o protagonista das mudanças nas escolas, é a partir dele que deve se desencadear as transformações necessárias para uma educação de melhor 
qualidade. Melhorar as condições de trabalho do professor é melhorar as condições de educação no país.

Assim, é preciso pensar para além das práticas escolares e mergulhar em questões de cunho político, corroborando com Silva (2011), que considera o investimento no professor como uma importante saída para a melhoria da qualidade do ensino envolvendo as TIC. Adicionem-se a isso as condições de trabalho e salário justos, investimento e qualidade na formação inicial e continuada dos professores.

A valorização da profissão docente deve ser um compromisso político que, a médio ou longo prazo, se comprometa a valorizar a profissão, possibilitando melhores condições de trabalho, equiparando o salário às categorias de nível superior, possibilitando uma única jornada ao professor.

Essa medida deve ser acompanhada de formação continuada constante, no intuito de sanar a lacuna geracional presente entre professores e alunos. Para Moran (2007, p. 90), a capacitação pedagógica ajuda a encontrar pontes entre as áreas de conhecimento em que atuam e as diversas ferramentas disponíveis. Os cursos ofertados para capacitação de professores têm que ser revistos e é preciso incentivar a prática reflexiva e propiciar espaços e tempos para troca de saberes e estudo coletivo.

A questão da infraestrutura e condição de trabalho aparecem como uma categoria fundamental para análise já que 79\% dos professores apontam não estarem preparados para usarem TIC em sala de aula, apesar de $90 \%$ acreditarem que há mudanças no processo de ensino/aprendizagem através de TIC. Nas entrevistas e nos questionários, muitos professores apontaram como fator impeditivo para o uso de TIC nas escolas a dificuldade de instalação e manutenção do aparato tecnológico, dificuldade que não tem como principal responsável o recurso financeiro e sim a problemas ligados a gestão e controle por parte da Secretaria de Educação do Estado de São Paulo.

Os elevados gastos com o aparato tecnológico devem refletir uma melhora na infraestrutura das escolas. É preciso gerir melhor esse dinheiro, de forma que se esclareça o processo burocrático para instar, consertar ou realizar a manutenção dos equipamentos das escolas. É preciso uma política clara e um planejamento coletivo que vise à implantação de TIC nas escolas ao mesmo tempo em que forme o professor e demais funcionários para usá-las de forma crítica e construtiva.

Sem estes fatores, não há tecnologia que dê conta de ensinar. Segundo Ioschpe (2012), o que há de errado com a educação não pode ser solucionado apenas com a 
tecnologia, uma vez que ensinar o mesmo conteúdo do livro na lousa digital não faz sentido, não promove mudanças. Dessa forma, conclui-se que as mudanças estão na busca por outras formas de ensinar fazendo uso de TIC, o que também passa por uma melhor gestão política para direcionamento delas não apenas como equipamento, mas como recurso pedagógico de aprendizagem.

Pela fala dos professores e pelas análises a partir das faixas etárias, observa-se que estamos em uma transição do quadro docente. Já há muitos professores da Rede que são "nativos digitais", mas, para a grande maioria, tudo é novo, ligar o computador e lidar com TIC no processo de ensino/aprendizagem ainda é um grande desafio.

Esse desafio apareceu nas falas dos professores, derivado em medo e insegurança. A inserção de TIC nas escolas fomenta a discussão sobre a crise da prática docente. É a primeira vez que se vê uma mudança tão brusca protagonizada pelos jovens sendo refletida nos âmbitos escolares. Essa transformação evoca a necessidade de romper de uma vez com os modelos conservadores de educação, que posiciona o professor como detentor do conhecimento e o aluno como um ser desprovido de conhecimento.

Para tanto, é preciso repensar práticas escolares, entender TIC como meio a mais de fomentar discussão crítica entre professores a fim de traçar caminhos que orientem prática docente criativa e reflexiva, em que TIC poderiam ser compreendidas como espaço de possibilidade de criação, individual ou colaborativa e não apenas utilizada como forma de chamar a atenção de alunos ou de sensibilizá-los aos conteúdos propostos na aula.

\section{Referências}

ARENDT, H. A crise na educação. In: Entre o passado e o futuro. Tradução de Mauro W. Barbosa de Almeida. $3^{\circ}$ reimpressão da 5 ed. de 2000. São Paulo: Perspectiva, 2005.

BAUMAN, Z. Modernidade Líquida. Tradução de Plínio Dentizien. Rio de Janeiro: Jorge Zahar Ed., 2001.

BELLONI, M. L. O que é mídia e educação. 2 ed. Campinas, v.29. n. 104.

BIANCHI, P; HATJE, M. A formação profissional em Educação Física permeada pelas tecnologias de informação e comunicação. Pensar a Prática. V. 10, n2, 291-306, jul./dez. 2007. 
BIZELLI, J. L. Inovação: limites e possibilidades para aprender na era do conhecimento. 1. ed. São Paulo: Editora Unesp/Cultura Acadêmica, 2013.

BIZELLI, J. L.; HEREDERO, E. S. Educação e inovação: o desafio da Escola Brasileira. Revista Tendéncias Pedagogicas (Universidad Autónoma de Madrid), v. 28, p. 55-66, 2016.

CAMBI, F. História da Pedagogia. São Paulo: UNESP, 1999.

CHAMPANGNATTE, D. M. O.; NUNES, L. C. A inserção das mídias audiovisuais no contexto escolar. Educação em revista, v. 27, v. 27, n. 3, p. 15-38. 2011.

DARIDO DA CUNHA, M.; SANTOS FILHO, J. R., SILVA, J. O ringue escolar: as meninas no tatame. In: Composição, Revista de Ciências Sociais da Universidade Federal do Mato Grosso do Sul. n. 12, Ano 17, p. 165-183. jun. 2013.

DARIDO DA CUNHA, M.; BIZELLI, J. L. Inovações tecnológicas e contexto escolar: reflexões necessárias. Revista Ibero-Americana de Estudos em Educação, v. 10, p. 50-66, 2015.2 Disponível em: <http://seer.fclar.unesp.br/iberoamericana/article/view/7772/5350>. Acesso em: $10 \mathrm{dez}$. 2016.

FOUCAUlT, M. Microfísica do Poder. Rio de Janeiro: Edições Graal, 1979.

FREIRE, P. Educação e Mudança. 14º edição. Rio de Janeiro: Paz e Terra, 1979. Coleção Educação e comunicação.

FRIDMANN, Luís Carlos. Pós-Modernidade: sociedade da imagem e sociedade do conhecimento. Hist. Cienc. Saud-Manguinhos. [online]. Jul/jul. 1999, vol 6, nº 2 [citdo 24 julho 2006], p. 353-375. Disponível em: $<$ http://www.scielo.br/scielo.phpscript=sci_arttex $\pi \mathrm{d}=9010459701999000300007 \&$ Ing= pt\&nrm=iso>. ISSN0104-5970.

GIDDENS, A. Modernidade e Identidade. Rio de Janeiro: Ed. Jorge Zahar, 2002.

KENSKI, V. M. Educação e tecnologias: o novo ritmo da informação. Campinas, SP: Papiros, 2007.

LEVY, P. A conexão planetária: o mercado, o ciberespaço, a consciência. São Paulo: Editora 34, 2004.

MAGALHÃES, C. M.; MILL. D. Elementos para reflexões sobre educação, comunicação e tecnologia: nada é tão novo sobre redes, linguagens e aprendizagem. Revista Educação: Temática Digital. V.2. 2014.

MISSIO, L.; CUNHA, J. L. Um olhar sobre a educação moderna no século XXI.. Disponível em: <http://coral.ufsm.br/gpforma/2senafe/PDF/056e4.pdf >. Acessado em 25 abr. 2016.

MORAN, J. M. Novas tecnologias e o re-encantamento do mundo. Tecnologia educacional, Rio de Janeiro. v. 23, n. 126, p. 24-26, set/out. 1995. 
PRETTO, N. L. Escritos sobre educação, comunicação e cultura. Campinas: Papirus, 2008.

SANCHO, J. A tecnologia: um modo de transformar o mundo carregado de ambivalência. In: SANCHO, J. M. (Org.). Para uma tecnologia educacional. Porto Alegre: Artmed, 1998. p. 22-49.

SHWARTZMAN, S. Educação Básica no Brasil: a agenda da modernidade. Revista Estudos Avançados. v.5 n. 13. 1991.

SILVA, M. Sala de aula interativa. Rio de Janeiro: Quartey, 2001.

TARDY, M. O professor e as imagens. São Paulo: Cultrix e USP, 1976.

VALENTE, J. A. As tecnologias e a verdadeira inovação. Pátio - Ensino Fundamental, Porto Alegre, v. 14, p 6-9, 2010. Disponível em: <www.grupoa.com.br/revista-patio/artigo/6315/as-tecnologias-e-a-verdeira-

inovação.aspx >. Acesso em: 08 abr. 2016.

\section{Como referenciar este artigo}

DARIDO DA CUNHA, Maíra.; BIZELLI, José Luís. Caminhos para TIC em sala de aula sob a perspectiva dos professores. Revista on line de Política e Gestão Educacional, Araraquara, v.20, n.2, p. 282-300, 2016. Disponível em: <http://dx.doi.org/10.22633/rpge.v20.n2.9458>. ISSN: 1519-9029.

Submetido em: junho/2016

Aprovado em: jul/2016 